\title{
(2) OPEN ACCESS \\ Allocation of funding into blast injury-related research and blast traumatic brain injury between 2000 and 2019: analysis of global investments from public and philanthropic funders
}

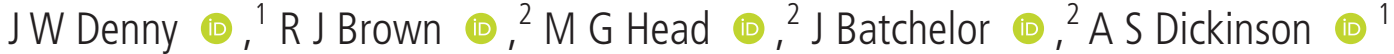

\begin{abstract}
- Additional material is published online only. To view, please visit the journal online (http://dx.doi.org/10.1136/ bmjmilitary-2020-001655).
\end{abstract}

${ }^{1}$ Bioengineering Science Research Group, School of Engineering, University of Southampton, Southampton, UK ${ }^{2}$ Clinical Informatics Research Unit, University of Southampton, Southampton, UK

\section{Correspondence to} Dr J W Denny, University of Southampton, Southampton S017 1BJ, UK; Jack.Denny@ soton.ac.uk

Received 17 September 2020 Revised 5 November 2020 Accepted 12 November 2020

\section{Check for updates}

(c) Author(s) (or their employer(s)) 2020. Re-use permitted under CC BY-NC. No commercial re-use. See rights and permissions. Published by BMJ.

To cite: Denny JW, Brown RJ Head MG, et al.

BMJ Mil Health Epub ahead of print: [please include Day Month Year]. doi:10.1136/ bmimilitary-2020-001655

\begin{abstract}
Introduction There is little systematic tracking or detailed analysis of investments in research and development for blast injury to support decision-making around research future funding.

Methods This study examined global investments into blast injury-related research from public and philanthropic funders across 2000-2019. Research databases were searched using keywords, and open data were extracted from funder websites. Data collected included study title, abstract, award amount, funder and year. Individual awards were categorised to compare amounts invested into different blast injuries, the scientific approaches taken and analysis of research investment into blast traumatic brain injury (TBI).

Results A total of 806 awards were identified into blast injury-related research globally, equating to US\$902.1 million ( $m, f 565.9 m$ GBP). There was a general increase in year-on-year investment between 2003 and 2009 followed by a consistent decline in annual funding since 2010. Pre-clinical research received $\$ 671.3 \mathrm{~m}$ (74.4\%) of investment. Brain-related injury research received $\$ 427.7$ m (47.4\%), orthopaedic injury $\$ 138.6 \mathrm{~m}(15.4 \%)$, eye injury $\$ 63.7 \mathrm{~m}(7.0 \%)$ and ear injury $\$ 60.5 \mathrm{~m}(6.7 \%)$. Blast TBI research received a total investment of $\$ 384.3$ $\mathrm{m}$, representing $42.6 \%$ of all blast injury-related research. The U.S. Department of Defense funded $\$ 719.3 \mathrm{~m}(80 \%)$. Conclusions Investment data suggest that blast TBI research has received greater funding than other blast injury health areas. The funding pattern observed can be seen as reactive, driven by the response to the War on Terror, the rising profile of blast TBI and congressionally mandated research.
\end{abstract}

\section{INTRODUCTION}

Blast injuries are a complex type of physical trauma resulting from direct or indirect exposure to an explosion. They range from internal organ injuries, including lung and blast traumatic brain injury (TBI), to orthopaedic injuries, burns, hearing and vision injuries. Following an explosive detonation, a combination of blast injury mechanisms (e.g. shock wave transmission, penetrating and blunt impacts) exert a variety of mechanical stresses on different tissues within the body. Explosions were reported to account for $78 \%$ of US combat injuries from 2001 to 2005 during the conflicts in Iraq and Afghanistan. ${ }^{1}$ Blast injury research aims to generate new understanding to predict, prevent or mitigate
Key messages

To our knowledge, this is the first study to describe the global landscape in-depth for al blast injury-related research from public and philanthropic funders.

- Our study covers 20 years of funding data, capturing long-term time trends and fluctuations of blast injury-related research, with a detailed focus on blast traumatic brain injury (TBI).

- Findings show that between 2000 and 2019, blast TBI has received significantly more research funding than other blast injury health areas such as orthopaedics and haemorrhage.

- The USA provides the majority of the global funding, in particular, the U.S. Department of Defense.

- Global stakeholders can use this evidence to inform best approaches to resource allocation, alongside other drivers for research prioritisation.

blast injuries, and improve clinical treatments and health outcomes.

Improvements in protection, combined with the changing nature of warfare and new explosive threats such as the improvised explosive device, have produced new patterns and types of injuries, generating new requirements for blast injury research. Improved personal protective equipment and operational patient care resulted in greater survival from blast injuries, bringing to the fore hitherto unseen challenges of functional recovery and rehabilitation and long-term effects of exposure to blast overpressure (e.g. blast TBI). ${ }^{2}$ Blastrelated brain injuries have become an increasing problem in recent conflicts-nearly $60 \%$ of US military personnel exposed to blast between 2003 and 2005 were diagnosed with some form of TBI. ${ }^{3}$ Despite the diagnostic ambiguities, blast TBI has been described as the 'signature injury' of the wars in Iraq and Afghanistan. ${ }^{4}$

Significant amounts of funding are allocated each year to global research in blast injury, spanning pre-clinical science, clinical trials, product development and public health. These allocations involve numerous stakeholders across the global health and defence communities, including funders, 
researchers, policymakers and clinicians. The new knowledge that emerges from research can be used as evidence to inform policy and practice.

However, there is little systematic tracking or detailed analysis of these investments to support decision-making around research funding. Furthermore, there is limited systematic coordination between stakeholders involved in funding research and development (R\&D), despite efforts such as the U.S. Department of Defense (US DoD) Blast Injury Research Coordinating Office, the Technical Cooperation Program and the North Atlantic Treaty Organization.

There is a need for an in-depth and comprehensive review of the global R\&D landscape to identify what research has taken place, who the funders were and what knowledge was generated. Such 'research on research' is critical for priority setting, informing funding decisions and to improve efficiency in allocating funds. ${ }^{5}$

We present research undertaken as part of the International Blast Injury Research Network (IBRN) ${ }^{6}$ on global investments into blast injury-related research, across 2000-2019 inclusive. We compare amounts invested into different blast injuries, the nature of research methodologies used and research pipeline. We have also undertaken a detailed analysis on research investment into blast TBI.

\section{METHODS}

The study considered awards related to human blast injury research from 24 global public and philanthropic funders (online supplemental information) made between 2000 and 2019. The methods are similar to other Research Investments in Global Health studies, ${ }^{7-9}$ which are briefly described here.

Data were manually collated from multiple sources. The majority of data (>90\%) was sourced from the UberResearch Dimensions database ${ }^{10}$ which includes 5.5 million awards across health and non-health R\&D sectors from 549 global funders (correct as of September 2020). Other data were sourced from websites of individual funders, funder databases such as the World Report, the UK Research and Innovation Grant Tracker, or by contacting the funder directly (online supplemental information).

Keyword searches and filters were applied to identify studies on injuries caused by explosive blasts, with their inclusion confirmed by further manual scrutiny by the authors who then categorised the awards with keyword labels (online supplemental information). Awards purely focused on modelling blast effects on vehicles, structures or protection systems were excluded, unless there was a clear human injury component. Excluded studies were manually reviewed to identify false negatives.

Secondary checks on all included awards were performed as per the study protocol. ${ }^{7-9}$ Inclusion and labelling of a total of 83 $(10 \%)$ awards in the final dataset were independently doublechecked by the coauthor. Where there was disagreement, data were provided to a third coauthor for consensus.

Award amounts were adjusted for inflation and converted to 2019 US dollars, using the average exchange rate in the award year. ${ }^{11} 12$ Award amounts were missing for 31 awards (3.7\%) from three funders (online supplemental information). Included award types comprised project and programme grants, fellowships, and pump-priming or pilot projects. Award types excluded were infrastructure grants and funding focused on implementation activities rather than research.

Labels applied to each award included injury type or health areas and type of science along the research pipeline (pre-clinical, phases 1-3 clinical trials, phase 4 and product development research, public health (focusing on populations) and cross-disciplinary awards). A cross-disciplinary award is defined here as a study covering more

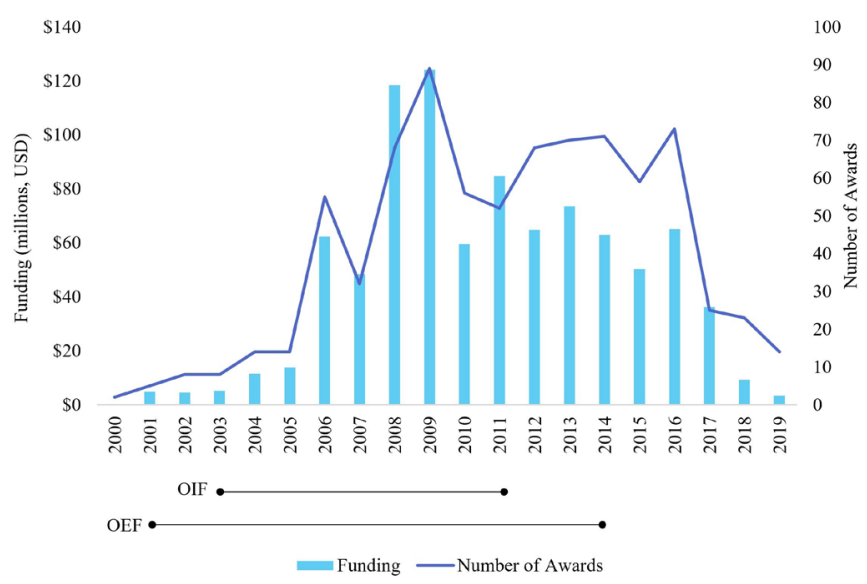

Figure 1 Investment into global blast injury-related research from 2000 to 2019.

than one stage of the research pipeline (e.g. preclinical research that progresses to a phase 1 study). Blast injury health area categories included both a range of systemic injuries (e.g. haemorrhage, cancer and infection) and injuries affecting specific anatomical regions (e.g. brain, lungs and eyes).

Awards focusing on brain health were categorised further to identify studies investigating blast TBI. Awards labelled as preclinical science were further categorised by their methodological approach, including in vivo, in vitro, in silico, inorganic models or combinations of these. Inorganic models include all physical experimental approaches where the main injury test subject is constructed using synthetic materials such as soft tissue simulants and anthropomorphic test devices. Awards with a clear product development component were categorised into therapeutics, diagnostics, prosthetics and orthotics. Therapeutics includes research relating to clinical treatments to prevent and treat blast injuries or the complications of a blast injury. Diagnostics includes research into screening, diagnosis and the development of diagnostics for blast injuries. Prosthetics and orthotics category includes any award with a focus on prosthetic and orthotic development and assessment.

\section{RESULTS}

Between 2000 and 2019 inclusive, 806 funding awards were made into blast injury-related research globally, with total funding of $\$ 902.1 \mathrm{~m}(£ 565.9 \mathrm{~m} \mathrm{GBP})$, giving a mean award value of $\$ 1.2 \mathrm{~m}(\mathrm{SD} \pm \$ 2.77 \mathrm{~m})$ and median award value of $\$ 0.5$ $\mathrm{m}$ (IQR 0.19-1.43 m) (Figure 1). There was a general increase in year-on-year investment for blast injury-related research between 2003 and 2009 followed by a consistent decline in annual funding since 2010 (Figure 1). Funding peaked in 2009 with a total investment of $\$ 124.0 \mathrm{~m}$ across 89 individual awards.

Along the research pipeline, pre-clinical research received $\$ 671.3 \mathrm{~m}(74.4 \%)$ across 600 awards (74.4\%). Public health research received \$110.6 $\mathrm{m}(12.3 \%)$ from 127 awards (15.7\%). Phase 1-3 trials received $\$ 86.7 \mathrm{~m}(9.6 \%)$ across 56 awards $(7.0 \%)$. Between 2000 and 2019, pre-clinical research generally received the highest proportion of investment each year (Figure 2). Phase 1-3 clinical trial awards had the largest median award size (\$1.1 $\mathrm{m}$, IQR $0.33-2.59 \mathrm{~m})$, compared with pre-clinical (\$0.6 m, IQR $0.26-1.39 \mathrm{~m}$ ), product development ( $\$ 0.4 \mathrm{~m}, \mathrm{IQR} 0.14-1.61 \mathrm{~m})$ or public health research $(\$ 0.1 \mathrm{~m}, \mathrm{IQR} 0.03-0.43 \mathrm{~m})$.

USA-based funders awarded the vast majority of investment into blast injury-related research, comprising 696 individual 


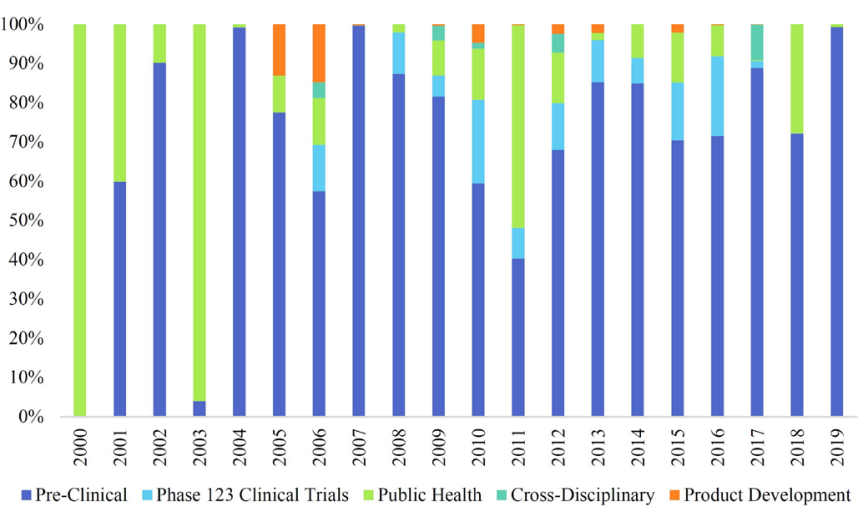

Figure 2 Blast injury-related research along the research pipeline from 2000 to 2019 by \% funding.

awards (86.4\%) and total funding of $\$ 883.4 \mathrm{~m}$ (97.9\%) (Table 1). The US DoD, was the largest funder investing a total of $\$ 719.3 \mathrm{~m}$ (79.7\%) across 485 individual awards (60.2\%) (Table 1). The second highest amount of total investment was awarded by the UK, comprising 23 individual awards (2.9\%) equating to a total of $\$ 11.1 \mathrm{~m}(1.2 \%)$ (Table 1$)$.
Investment into brain-related blast injury research received the largest proportion of funding totalling $\$ 427.7 \mathrm{~m} \mathrm{(47.4 \% )} \mathrm{across}$ 385 awards (47.8\%) (Figure 3), followed by orthopaedic blast injuries (\$138.5 m (15.4\%) from 102 awards). Research into blast injuries to the eyes and ears received total global investments of $\$ 63.7 \mathrm{~m}(7.0 \%)$ across 52 awards and $\$ 60.5 \mathrm{~m}(6.7 \%)$ across 47 awards, respectively. Blast injury research concerning 'polytrauma' received a total investment of $\$ 8.2 \mathrm{~m}(0.9 \%)$ across eight awards.

Blast TBI research received $\$ 384.3 \mathrm{~m}$ across 377 awards, representing $42.6 \%$ of all blast injury-related research. This was $89.9 \%$ of funding, and $97.9 \%$ of awards focused on the brain. Investment into blast TBI research followed a similar funding trend to broader blast injury-related research. Following inconsistent trends between 2000 and 2005, investment into blast TBI research increased markedly in 2006, reaching a peak in 2009 where $\$ 68.3 \mathrm{~m}$ was invested across 52 individual awards (Figure 4). Thereafter, blast TBI funding levels were sustained, with annual fluctuations, until 2016, after which investment has steadily declined (Figure 4).

By areas of the research pipeline, $\$ 294.5 \mathrm{~m} \mathrm{(76.6 \% )}$ across 280 awards $(74.2 \%)$ was for investment into pre-clinical blast TBI research, with $\$ 34.6 \mathrm{~m}$ (9.0\% of funding) for phase 1-3

\begin{tabular}{|c|c|c|c|c|}
\hline Funder country and funder & Awards (n) & $\%$ Awards & Funding (\$) & $\%$ Funding \\
\hline Canada & 8 & 1.0 & 846473 & 0.1 \\
\hline Canadian Institutes of Health Research & 5 & 0.6 & 604929 & 0.1 \\
\hline Natural Sciences and Engineering Research Council & 2 & 0.2 & 160694 & $<0.1$ \\
\hline Saskatchewan Health Research Foundation & 1 & 0.1 & 80850 & $<0.1$ \\
\hline China & 5 & 0.6 & 256982 & $<0.1$ \\
\hline National Natural Science Foundation of China & 5 & 0.6 & 256982 & $<0.1$ \\
\hline Denmark & 1 & 0.1 & 428077 & $<0.1$ \\
\hline Danish Ministry of Higher Education and Science & 1 & 0.1 & 428077 & $<0.1$ \\
\hline France & 2 & 0.2 & 702097 & 0.1 \\
\hline National Agency for Research & 2 & 0.2 & 702097 & 0.1 \\
\hline Germany & 1 & 0.1 & 239940 & $<0.1$ \\
\hline German Research Foundation & 1 & 0.1 & 239940 & $<0.1$ \\
\hline Japan & 67 & 8.3 & 4689537 & 0.5 \\
\hline Japan Society for the Promotion of Science & 67 & 8.3 & 4689537 & 0.5 \\
\hline South Africa & 1 & 0.1 & Not available & - \\
\hline National Research Foundation & 1 & 0.1 & Not available & - \\
\hline Sweden & 2 & 0.2 & 448240 & $<0.1$ \\
\hline VINNOVA & 2 & 0.2 & 448240 & $<0.1$ \\
\hline UK & 23 & 2.9 & 11130884 & 1.2 \\
\hline Defence Science and Technology Laboratory & 16 & 2.0 & 2386147 & 0.3 \\
\hline UK Research and Innovation & 5 & 0.6 & 2360043 & 0.3 \\
\hline National Institute for Health Research & 2 & 0.2 & 6384694 & 0.7 \\
\hline USA & 696 & 86.4 & 883395635 & 97.9 \\
\hline U.S. Department of Defense & 485 & 60.2 & 719342999 & 79.7 \\
\hline United States Department of Veterans Affairs & 92 & 11.4 & 30665507 & 3.4 \\
\hline National Institutes of Health & 67 & 8.3 & 104216608 & 11.6 \\
\hline Center for Neuroscience and Regenerative Medicine & 31 & 3.8 & 20430353 & 2.3 \\
\hline National Science Foundation & 13 & 1.6 & 4085677 & 0.5 \\
\hline Centers for Disease Control and Prevention & 3 & 0.4 & 590031 & 0.1 \\
\hline Citizens United for Research in Epilepsy & 1 & 0.1 & 3066605 & 0.3 \\
\hline United States Department of Health and Human Services & 1 & 0.1 & 944855 & 0.1 \\
\hline Health Reimbursement Arrangement & 1 & 0.1 & 52999 & $<0.1$ \\
\hline National Aeronautics and Space Administration & 1 & 0.1 & Not available & - \\
\hline U.S. Food and Drug Administration & 1 & 0.1 & Not available & - \\
\hline
\end{tabular}




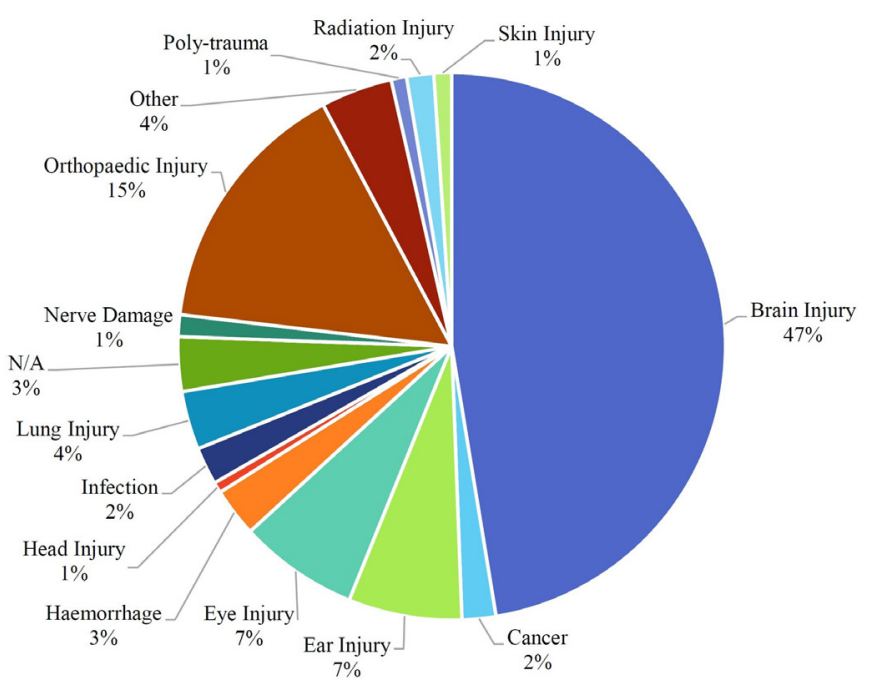

Figure 3 Proportions of research investment into different blast injury health areas. N/A, not applicable.

clinical trials and $\$ 35.1 \mathrm{~m}(9.1 \%)$ for public health research (Figure 4).

Blast TBI research concerned with therapeutic products received a total investment of $\$ 90.8 \mathrm{~m}(23.6 \%$ of all blast TBI research funding) across 70 awards. Investment into blast TBI diagnostics totalled $\$ 89.3 \mathrm{~m}$ (23.2\% of all blast TBI research funding) across 60 awards. The majority of funding into both therapeutics and diagnostics was invested into studies at the pre-clinical stage of the research pipeline, receiving $\$ 59.6 \mathrm{~m}$ and $\$ 55.2 \mathrm{~m}$, respectively (Figure 5). Investment into phase 1-3 clinical trials for therapeutic products for blast TBI $(\$ 23.4 \mathrm{~m})$ was over double that invested in diagnostic products research $(\$ 11.2 \mathrm{~m})$. Larger research investments were made into product development and public health research awards relating to blast TBI diagnostics in comparison to therapeutics (Figure 5).

Approximately half $(48.7 \%)$ of the investment into preclinical blast TBI research has described solely the use of in vivo approaches, receiving $\$ 143.4 \mathrm{~m}$ across 137 awards (online supplemental information, figure A). Studies with an in vitro approach received an investment of $\$ 28.4 \mathrm{~m}$ (9.7\%) across 15 awards. In silico and inorganic modelling studies for blast TBI

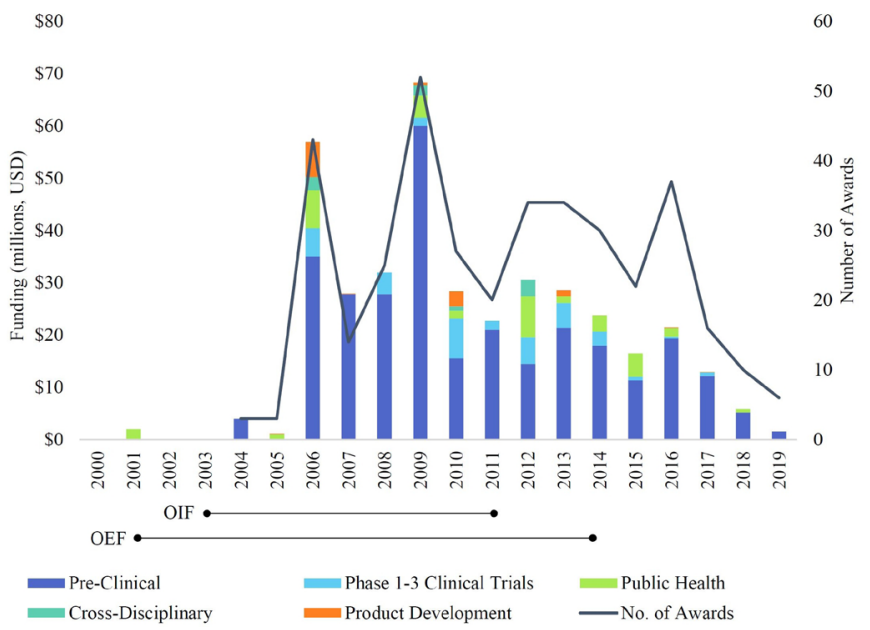

Figure 4 Investment into global blast traumatic brain injury research from 2000 to 2019.

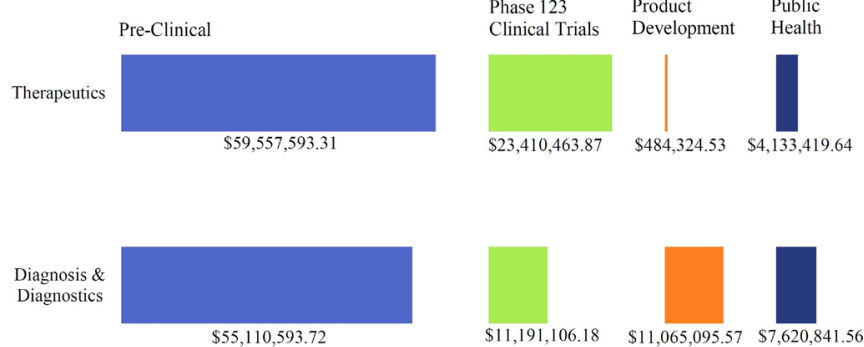

Figure 5 Investment into blast traumatic brain injury research products (therapeutics and diagnostics) along the research pipeline. Online supplemental information, figure $\mathrm{A}$

received total investments of $\$ 17.5 \mathrm{~m}(6.0 \%)$ across 10 studies and $\$ 7.1 \mathrm{~m} \mathrm{(2.4 \% )}$ across four studies, respectively.

\section{DISCUSSION}

This study reports on nearly $\$ 1$ billion of public and philanthropic funding invested into blast injury-related research over 2000-2019 inclusively. Annual funding levels and the number of awards varied considerably over this time, with a noticeable increase starting in 2003 that peaked in 2008 and 2009. Thereafter, there was reduced but relatively well-sustained activity before a decline from 2016.

Understanding the multiple drivers of research investment is complex. Many factors influence research funding decisions, such as burden of disease, political drivers of decisionmaking (notable here, given the major funder is the US DoD), advocacy and lobbying, emergency preparedness for terrorism, conflicts and other humanitarian responses. With $80 \%$ of global research funding coming from the US DoD, it is clear that blast injury science is a defence-driven field that is largely influenced by changes in US military expenditure, which will depend on changing priorities, requirements, and political drivers. ${ }^{13}$ Funding trends show a correlation with broader US military spending during the time period. Data from the Stockholm International Peace Research Institute shows that US military spending rose sharply after the terrorist attacks of 2001, reaching a peak in 2010 before falling in recent years. ${ }^{14}$

Investment into blast injury research appears to have been significantly influenced by major conflict activity, namely, the War on Terror, launched by the US government after the 11 September 2001 attacks. Most notably, this included the US-led ground invasions of Afghanistan, Operation Enduring Freedom (OEF) from October 2001 - December 2014 and Iraq, Operation Iraqi Freedom (OIF) from March 2003 to December 2011. Given the context of these major conflicts, several factors will have influenced temporal investment levels into blast injury research, such as the rate of military operations, levels of deployed military personnel, casualty reporting and defence budgets. It can be seen, as an example, that blast injury-related research investment began to noticeably increase from 2003, which coincides with the start of OIF. Blast injury research investment significantly increased and peaked in 2008 and 2009 (Figure 1). This corresponds to a time period of accelerating US combat activity, high levels of military deployment, increasing casualty numbers and budgets among other factors, contributing to the allocation of additional funding in blast injury-related research. ${ }^{15}$ Prolonged involvement in OEF (Afghanistan) until late 2014 and research investment lag times in responding to requirements driven by casualty reports are likely to explain the sustained interest and investment into blast injury research 
beyond the peak in 2009. Declines in investment since 2016 coincide with reduced US operations in the Middle East and reduced US military spending. ${ }^{14}$ This decline in investment mirrors a recurrent cyclical pattern observed after other conflicts, known as the 'Walker Dip, ${ }^{16}$ whereby medical care improves during conflicts, the lessons are forgotten after and have to be relearned again during the next war, thus repeating the cycle.

Analogous to infectious disease research investment reacting to major epidemics (eg, Ebola, COVID-19 and SARS), ${ }^{7}$ results in this paper show that funding into blast injury-related research has been reactive and influenced by the US involvement and operations in the Middle East conflicts and overall US military funding levels. Following the end of these conflicts and with increasingly constrained budgets, justifying an appropriate level of investment into blast injury science to maintain capability will become increasingly challenging, potentially reflected in the reduced funding in 2017-2019.

Findings show that blast TBI research is a priority topic in the blast injury landscape over 2000-2019. Funding into blast TBI drives the trend observed across the field. The allocation of funding for blast TBI and changes in funding levels appear to have been driven by several factors relating to the US involvement in the Middle East conflicts. Analyses by the Defence and Veterans Brain Injury Centre on data from military patients identified symptomologies related to mild-blast or moderateblast TBI up to several months post-injury that were hypothesised to be related to exposure (especially repeated exposure) to explosions and blast overpressure. ${ }^{17} 18$ Throughout OIF and OEF, increasing cases of blast TBI or suspected mild TBI were diagnosed. Becoming known as the 'signature injury' of the Iraq conflict, ${ }^{4}$ blast TBI gained a sufficiently high profile for the US Congress to increase funding specifically for blast TBI research. The US Congress added $\$ 150 \mathrm{~m}$ in research funding to the 2007 DoD supplemental appropriation designated for blast TBI and another $\$ 150 \mathrm{~m}$ for PTSD and in 2008, a supplemental appropriation earmarked $\$ 270 \mathrm{~m}$ for a broad Combat Casualty Care Research agenda, plus another $\$ 70 \mathrm{~m}$ for blast TBI. ${ }^{13}$ The increasing profile of blast TBI and mobilisation of additional funding from the US government during 2007-2008 explains the significant peak of research awards made during 2009. Similar to all blast injury areas, an overall decline in investment into blast TBI research since 2016 likely relates to reduced activities and withdrawal of military personnel from Middle East conflicts.

In comparison to other traumatic, high-impact injuries (e.g. falls, vehicle accidents resulting in crush and orthopaedic injuries), some injury types resulting from blast exposure require specific blast injury research activity. In particular, so-called 'primary' blast injuries, resulting from pure shock wave interaction with human tissues, ${ }^{19}$ present a unique series of injuries that particularly affect gas-containing or liquid-containing organs, for example, the lungs, bowel, ears, eyes and, more recently, linked to blast TBI.

When considering priority setting and how future research funding should be allocated, it is important not to overlook that while particular injury areas may have received extensive funding in the past (e.g. the brain), significant knowledge gaps may still remain. Only through detailed analysis and comparison with epidemiological data, and consideration of the economic burden of blast injury can we begin to evaluate how appropriate such investment was, the extent that the research funding portfolio is balanced and addresses priorities and future research investments. It is also highlighted that research funds should be directed towards solving prehospital clinical problems and balanced to include research on training, organisation and leadership, not just material solutions. ${ }^{20}$

This study has several limitations. There will be missing data, in particular where data could not be accessed from public and philanthropic funders and where activity is occurring as part of classified research commissioned by defence departments. Given the nature of this research area, this is likely to be substantial. A key challenge was integrating data that were presented in numerous different formats. As discussed in previous Research Investments in Global Health(RESIN) analyses, ${ }^{7}$ future work would be simplified considerably if funders could adopt a 'minimum dataset' of required information. Applying categories to an award retrospectively is time-consuming and subjective, although errors have been reduced with observations from a second author and consensus. Automated categorisation based on keyword searches is problematic since the title and abstract of many awards contain references to injuries and scenarios that are not the study area of focus. The study also lacks data from the private sector.

\section{CONCLUSION}

Since priority setting for research must consider many different factors, this analysis should be viewed as evidence to support decision-making rather than one providing clear-cut answers. Comparison of these results with blast injury epidemiological data would permit a deeper evaluation of the research portfolio to more clearly define the human burden of blast injury and therefore support decisionmaking and priority setting. Findings suggest steps should be taken to encourage a broader, interdisciplinary effort to address contemporary blast injury challenges. A high incidence of civilian blast injuries is a reminder that continued blast injury research is essential, although efforts should be diversified to ensure broader advancements and benefit for both military and civilian care.

\section{Twitter JW Denny @JackWDenny}

Acknowledgements The majority of data was sourced by accessing the Dimensions database, owned by UberResearch (https://www.dimensions.ai/). We acknowledge all funders who directly or indirectly provided data and those who provided information about and links to the funders. The allocation of funding into blast injury-related research and blast traumatic brain injury between 2000 and 2019: an analysis of global investments from public and philanthropic funders.

Contributors JWD: literature search, figures, study design, data collection, data analysis, data interpretation and writing. RJB: literature search, figures, study design, data collection, data analysis, data interpretation and writing. MGH: data analysis, data interpretation, writing and review. JB: data interpretation, writing and review. ASD: writing and review.

Funding The authors gratefully acknowledge support from: RAEng Frontiers of Development Seed Funding, EPSRC Doctoral Prize, The Global Challenges Research Fund and The Royal Academy of Engineering (award number RF/130).

Competing interests None declared.

Patient consent for publication Not required.

Provenance and peer review Not commissioned; externally peer reviewed.

Data availability statement Data are available upon reasonable request. For more information or access to datasets, please contact the corresponding author.

Supplemental material This content has been supplied by the author(s). It has not been vetted by BMJ Publishing Group Limited (BMJ) and may not have been peer-reviewed. Any opinions or recommendations discussed are solely those of the author(s) and are not endorsed by BMJ. BMJ disclaims all liability and responsibility arising from any reliance placed on the content. Where the content includes any translated material, BMJ does not warrant the accuracy and reliability of the translations (including but not limited to local regulations, clinical guidelines, 
terminology, drug names and drug dosages), and is not responsible for any error and/or omissions arising from translation and adaptation or otherwise.

Open access This is an open access article distributed in accordance with the Creative Commons Attribution Non Commercial (CC BY-NC 4.0) license, which permits others to distribute, remix, adapt, build upon this work non-commercially, and license their derivative works on different terms, provided the original work is properly cited, appropriate credit is given, any changes made indicated, and the use is non-commercial. See: http://creativecommons.org/licenses/by-nc/4.0/.

\section{ORCID iDs}

J W Denny http://orcid.org/0000-0003-3181-4747

R J Brown http://orcid.org/0000-0001-5825-6859

M G Head http://orcid.org/0000-0003-1189-0531

J Batchelor http://orcid.org/0000-0002-5307-552X

A S Dickinson http://orcid.org/0000-0002-9647-1944

\section{REFERENCES}

1 Owens BD, Kragh JF, Wenke JC, et al. Combat wounds in operation Iraqi freedom and operation enduring freedom. J Trauma 2008;64:295-9.

2 Schneiderman Al, Braver ER, Kang HK. Understanding sequelae of injury mechanisms and mild traumatic brain injury incurred during the conflicts in Iraq and Afghanistan: persistent postconcussive symptoms and posttraumatic stress disorder. Am J Epidemiol 2008;167:1446-52.

3 Okie S. Traumatic brain injury in the war zone. N Engl J Med 2005;352:2043-7.

4 Xydakis MS, Robbins AS, Grant GA. Mild traumatic brain injury in U.S. soldiers returning from Iraq. N Engl J Med 2008;358:2177-80.

5 World Bank Group. Money and microbes : strengthening clinical research capacity to prevent epidemics (English). Washington D.C, 2018. Available: https://doi.org/10. 1126/science.301.5637.1182b
6 IBRN. The International blast injury research network (IBRN), 2019. Available: www. blastinjurynetwork.com

7 Head MG, Brown RJ, Newell M-L, et al. The Allocation of US\$ 105 Billion in Global Funding for Infectious Disease Research between 2000 and 2017: An Analysis of Investments from Funders in the G20 Countries. SSRN 2020.

8 Head MG, Fitchett JR, Nageshwaran V, et al. Research investments in global health a systematic analysis of UK infectious disease research funding and global health metrics, 1997-2013. EBioMedicine 2016:3:180-90.

9 Brown RJ, Head MG. Sizing up pneumonia investment. J Contribution 2018.

10 Dimensions. Available: https://www.dimensions.ai/

11 Antweiler W. The University of British Columbia Sauder school of business Pacific exchange rate service, 2020. Available: http://fx.sauder.ubc.ca/data.html

12 UKForex Limited. Historical exchange rates, 2020. Available: https://www.ofx.com/engb/forex-news/historical-exchange-rates/

13 Champion HR, Holcomb JB, Young LA. Injuries from explosions: physics, biophysics, pathology, and required research focus. J Trauma 2009;66:1468-77.

14 Stockholm International Peace Research Institute (SIPRI). Military expenditure by country, in constant (2018) US\$ m., 1988-2019, 2020.

15 Peters HM, Plagakis S. Department of defense contractor and Troop levels in Afghanistan and Iraq: 2007-2018, 2019.

16 Walker AJ. The 'Walker dip'. J R Nav Med Serv 2018;104:173-6.

17 Martin EM, Lu WC, Helmick K, et al. Traumatic brain injuries sustained in the Afghanistan and Iraq wars. Am I Nurs 2008;108:40-7.

18 The Management of Concussion/mTBI Working Group. Va / DOD clinical practice guideline for management of concussion / mild traumatic brain injury the management of concussion / mTBI Working group, 2009. Available: https://doi.org/10. 1682/JRRD.2009.06.0076

19 Stuhmiller JH. Blast injury translating research into operational medicine, 2010.

20 Mabry RL, DeLorenzo R. Challenges to improving combat casualty survival on the battlefield. Mil Med 2014:179:477-82. 